\title{
Hand abnormalities in diabetics: Prevalence and predictors in Erbil city
}

Accepted: 22/9/2016

\begin{tabular}{cc}
\hline Niaz J. Al-Barzinji * & Wallada Khalid Mohammed ** \\
\hline & Abstract
\end{tabular}

Background and objective: The characteristics of diabetic foot disease are well documented in Erbil city; henceforth it would be appropriate to evaluate the problem of diabetic hand syndrome in this environment and to assess the frequency and the most important clinical and biochemical risk factors for the development of these complications.

Methods: This is an observational case-control study done over a period of one year. A total of 100 consecutive patients with type 2 diabetes mellitus were enrolled and described as cases. One hundred age- and sex-matched nondiabetic individuals were taken in the control group; all were examined and then underwent the appropriate investigations.

Results: Of the total 100 diabetic patients, 63\% had macrovascular complications and $60 \%$ had one or more hand disorders. Limited joint mobility (47\% vs. $18 \%$, respectively; $P=0.0001)$ and Dupuytren's contracture (16\% vs. $2 \%$, respectively; $P=0.001)$ were significantly higher in type 2 diabetes mellitus patients than in the controls, but not trigger finger. These hand soft-tissue changes correlated significantly with poor glycemic control.

Conclusion: This study shows a high prevalence of hand disorders in diabetic patients with the limited joint mobility being the most common hand disorder. The hand soft tissue changes are under recognized in diabetic patients, occurring in $60 \%$ of the cases. We recommend that physicians should consider examining the periarticular region of the joints in the hands in each diabetic patient.

Keywords: Diabetes mellitus; Dupuytren's contracture; Trigger finger; Limited joint mobility; Hand soft tissues changes.

\section{Introduction}

Musculoskeletal complications of diabetes mellitus (DM) are the most common endocrine arthropathies. These have been generally under recognized and poorly treated compared with other complications, such as neuropathy, retinopathy, and nephropathy. These manifestations, which are some of the causes of chronic disability, involve not only the joints but also the bones and the soft tissues. ${ }^{1}$ Diabetes is complicated by musculoskeletal problems of upper extremity and particularly the hand, which called "the diabetic hand." The term includes limited joint mobility (LJM) that occur particularly in Diabetes Mellitus in addition to the non diabetic hand changes, such as trigger finger and Dupuytren's contracture. ${ }^{2}$ Limited joint mobility is a painless and nondisabling complication of diabetes caused by thickening and stiffness of periarticular connective tissues. It involves the small joints of the hand and is often neglected until hand deformity is severe enough to interfere with daily life. Patients with LJM typically have limited extension of the metacarpophalangeal, proximal and distal interphalangeal joints, generally beginning in the ulnar digits and spreading radially. Limited joint mobility has been recognized as the most common and earliest long-term complication of type I $\mathrm{DM}$ and it also occurs in type $2 \mathrm{DM}^{3}$ Trigger finger (TF), one of the most common causes of hand pain and

* Department of I nternal Medicine, College of Medicine, Hawler Medical University, Erbil, I raq.

** Erbil Directorate of Health, Erbil, I raq. 
disability, the flexor tendon causes painful popping or snapping as the patient flexes and extends the digit. The patient may present with a digit locked in a particular position, most often flexion, which may require gentle, passive manipulation into full extension ${ }^{4}$ Studies have shown that, compared with a nondiabetic population, trigger finger in diabetic patients is more common in female patients, more often bilateral, more often multidigit, and relatively sparing the index and small fingers. ${ }^{5}$ Dupuytren's contracture is a progressive disorder that affects the palmar fascia, causing the fibrous tissue to shorten and thicken. ${ }^{6}$ Excessive myofibroblast proliferation and altered collagen matrix composition lead to thickened and contracted palmar fascia. The resultant digital flexion contractures may severely limit function. ${ }^{7}$ The prevention and treatment of the complications of chronic diseases depend on understanding their prevalence and risk factors ${ }^{8}$. In Erbil city, there is a lack of reports that describe the hand soft tissue changes in diabetic patients. No previous studies had been conducted to assess the prevalence of hand soft tissue changes in diabetic patients or to evaluate the predisposing factors. Thus, the aim of this study was to evaluate the frequency of hand manifestations in adult diabetic patients visiting Rizgary Teaching Hospital in Erbil city and to identify their predictors.

\section{Methods}

A total of 100 consecutive patients with type 2DM and 100 age, gender matched non-diabetic controls were examined for hand changes. Patients were included provided they had a history of DM for at least two years, diagnosed according to the World Health Organization (WHO) diagnostic criteria as a fasting plasma glucose level of $126 \mathrm{mg} / \mathrm{dL}(7.0 \mathrm{mmol} / \mathrm{l}){ }^{9}$ The study was carried out at Rizgary Teaching Hospital in Erbil city and was approved by the Institute's ethics committee. Subjects with known connective tissue disorders, rheumatoid arthritis, infective arthritis, gouty arthritis, end stage renal disease, thyroid disorders, chronic liver disease and a history of antiepileptic drug use were excluded. All subjects were undergone through a thorough clinical examination. The demographic parameters [age, gender and body mass index (BMI)] were noted on each subject. All findings were objectively recorded according to the following definitions: The prayer sign and flattening sign were used for qualitative assessment of limited joint mobility. The prayer sign is described as the inability to fully flatten the two palms when opposed and clasped together. The flattening sign is described as the inability to fully flatten the palm on a flat surface. ${ }^{10}$ LJM farther staged using Brink-Starkman classification system: ${ }^{11}$ stage 0 , no abnormality; stage 1 , skin thickening with no contracture; stage 2 , bilateral fifth finger contracture; stage 3 , other fingers involved bilaterally; stage 4, bilateral finger and wrist involvement; and stage 5, bilateral finger, wrist and other joint involvement. Flexor tenosynovitis or stenosing tenosynovitis or trigger finger was diagnosed by palpating a nodule or thickened flexor tendon with locking phenomenon during finger flexion or extension. The diagnosis of Dupuytren's contracture was based on one of the following features: a palmar or digital nodule; tethering of palmar or digital skin; a pretendinous band and a digital flexion contracture, palpable thickening of the palmar fascia, with a flexor deformity of the second, third, fourth, or fifth fingers. ${ }^{12}$ Regarding the macrovascular complications is a disease of large blood vessels in the body including the coronary arteries, the aorta, and the sizable arteries in the brain and the limbs. ${ }^{13}$ We also recorded the hemoglobin $\mathrm{A} 1 \mathrm{C}$ (HbA1C) levels of the patients, measured by immunoassay, using the COBAS C311 chemistry analyzer. Poor glycemic control was considered when HbA1c levels were more than $6.5 \%$ according to the recommendations of the World Health 
Organization (WHO) which considered An HbA1c of $48 \mathrm{mmol} / \mathrm{mol}(6.5 \%)$ is recommended as the cut-off point for diagnosing diabetes. ${ }^{14}$ While the nondiabetic controls underwent blood glucose examination after an (8 to 10) hours overnight fast, and only those with fasting plasma glucose (FPG) of less than 100mg/ $\mathrm{dL}$ were recruited for the study.

Data management and statistical analysis:

Data recorded on a specially designed questionnaire, collected and entered into the computer and then analyzed using appropriate data system which is called the statistical package for the social sciences (version 22). The results were compared between patients with different variables, with a statistical significance level of $<0.05$. The results were presented as rates, ratio, frequencies, percentages in tables and figures. Chi square and t-tests were performed to compare between both groups. Binary logistic regression was done to predict the most important factors contributing to the occurrence of different hand disorders.

\section{Results}

Except for MVC, there were non-significant statistical relationships between study groups and baseline characteristics. The cases did not differ from controls regarding all baseline features except MVC in which most cases (63\%) had complications in contrast to control patients in which most of them (66\%) did not develop MV complications $(P>0.05)$ as shown in Table 1. The age \pm SD of cases $(59.3 \pm 8.5)$ was matched to that of the control group (59.7 \pm 7.1). There was no difference between them $(P=0.73)$.

Table 1: Baseline characteristics of study samples.

\begin{tabular}{|c|c|c|c|c|}
\hline \multirow{2}{*}{ Parameters } & \multirow{2}{*}{ Categories } & \multicolumn{2}{|c|}{ Study samples } & \multirow{2}{*}{$P$ value } \\
\hline & & Cases & Controls & \\
\hline \multirow[t]{2}{*}{ Gender } & Male & $51(49.5 \%)$ & $52(50.5 \%)$ & \multirow[b]{2}{*}{0.88} \\
\hline & Female & $49(50.5 \%)$ & $48(49.5 \%)$ & \\
\hline \multirow[t]{2}{*}{ MVC } & Yes & $63(64.9 \%)$ & $34(35.1 \%)$ & \multirow[b]{2}{*}{0.0001} \\
\hline & No & $37(35.1 \%)$ & $66(64.9 \%)$ & \\
\hline \multirow[t]{3}{*}{ Smoking } & Yes & $15(44.1 \%)$ & 19(55.9\%) & \multirow{3}{*}{0.32} \\
\hline & No & $67(48.9 \%)$ & $70(51.1 \%)$ & \\
\hline & Ex-smoker & $18(62 \%)$ & $11(38 \%)$ & \\
\hline \multirow[t]{3}{*}{ BMI } & Normal & $24(41.4 \%)$ & $34(58.6 \%)$ & \multirow{3}{*}{0.25} \\
\hline & Overweight & $67(52.7 \%)$ & $60(47.3 \%)$ & \\
\hline & Obese & $9(60 \%)$ & $6(40 \%)$ & \\
\hline \multirow[t]{2}{*}{ Manual labour } & Yes & $38(55 \%)$ & $31(45 \%)$ & \multirow{2}{*}{0.29} \\
\hline & No & $62(47.3 \%)$ & $69(25.7 \%)$ & \\
\hline
\end{tabular}


There was a significant statistical relationship between study groups and $\mathrm{LMJ}$ and DC. The prevalence of LMJ was higher among cases (47\%) while only (18\%). The same for DC, diabetic patients had more DC (16\%) in comparison to only $(2 \%)$ of non-diabetic patients $(P<0.05)$. There was a non-significant statistical association between study groups and TF. The vast majority of both groups did not have TF. $9 \%$ of cases and $6 \%$ of controls had TF $(P=0.42)$. The details are shown in Table 2. There was a significant statistical association between hand disorders and $\mathrm{HbA} 1 \mathrm{c}$ levels. LMJ, DC and TF were more prevalent in patients with HbA1c concentrations higher than 6.5 units in comparison to lower levels $(P<0.05)$. In contrast, there was a non-significant statistical relationship between hand disorders and duration of diabetes and MVC $(P>0.05)$ as shown in Table 3.

Table 2: Distribution of various hand disorders among cases and controls.

\begin{tabular}{|c|c|c|c|c|}
\hline \multirow{2}{*}{ Parameters } & \multirow{2}{*}{ Categories } & \multicolumn{2}{|c|}{ Study samples } & \multirow{2}{*}{$P$ value } \\
\hline & & Cases & Controls & \\
\hline \multirow[t]{2}{*}{ LJM } & Present & $47(72.3 \%)$ & $18(37.7 \%)$ & \multirow[b]{2}{*}{0.0001} \\
\hline & Absent & $53(28 \%)$ & $82(72 \%)$ & \\
\hline \multirow[t]{2}{*}{ DC } & Present & 16(88.9\%) & $2(11.1 \%)$ & \multirow[b]{2}{*}{0.001} \\
\hline & Absent & $84(46.1 \%)$ & $98(53.9 \%)$ & \\
\hline \multirow[t]{2}{*}{ TF } & Present & $9(60 \%)$ & $6(40 \%)$ & \multirow{2}{*}{0.42} \\
\hline & Absent & $91(49.1 \%)$ & $94(50.9 \%)$ & \\
\hline
\end{tabular}

Table 3: Distribution of hand disorders among cases in relation to HbA1c, duration of DM and MVC.

\begin{tabular}{|c|c|c|c|c|c|c|c|c|c|}
\hline \multirow[b]{2}{*}{ Variable } & \multicolumn{2}{|c|}{$\mathrm{Hb}$ A1c } & \multirow[b]{2}{*}{$P$ value } & \multicolumn{2}{|c|}{ Duration of DM } & \multirow[b]{2}{*}{$P$ value } & \multicolumn{2}{|c|}{ MVC } & \multirow[b]{2}{*}{$\begin{array}{c}P \\
\text { value }\end{array}$} \\
\hline & $\begin{array}{l}<6.5 \\
(n=6)\end{array}$ & $\begin{array}{c}\geq 6.5 \\
(n=66)\end{array}$ & & $\begin{array}{c}\geq 10 \text { years } \\
(n=37)\end{array}$ & $\begin{array}{c}<10 \text { years } \\
(n=35)\end{array}$ & & $\begin{array}{c}\text { Yes } \\
(n=49)\end{array}$ & $\begin{array}{c}\text { No } \\
(n=23)\end{array}$ & \\
\hline LJM & $\begin{array}{c}5 \\
(10.6 \%)\end{array}$ & $\begin{array}{c}42 \\
(89.4 \%)\end{array}$ & 0.001 & $\begin{array}{c}24 \\
(51 \%)\end{array}$ & $\begin{array}{c}23 \\
(49 \%)\end{array}$ & 0.18 & $\begin{array}{c}33 \\
(70 \%)\end{array}$ & $\begin{array}{c}14 \\
(30 \%)\end{array}$ & 0.15 \\
\hline DC & $\begin{array}{c}1 \\
(6.2 \%)\end{array}$ & $\begin{array}{c}15 \\
(93.8 \%)\end{array}$ & 0.01 & $\begin{array}{c}9 \\
(56.3 \%)\end{array}$ & $\begin{array}{c}7 \\
(43.7 \%)\end{array}$ & 0.87 & $\begin{array}{c}8 \\
(50 \%)\end{array}$ & $\begin{array}{c}8 \\
(50 \%)\end{array}$ & 0.24 \\
\hline TF & $\begin{array}{c}0 \\
(0 \%)\end{array}$ & $\begin{array}{c}9 \\
(100 \%)\end{array}$ & 0.02 & $\begin{array}{c}4 \\
(44.4 \%)\end{array}$ & $\begin{array}{c}5 \\
(55.6 \%)\end{array}$ & 0.38 & $\begin{array}{c}8 \\
(88.9 \%)\end{array}$ & $\begin{array}{c}1 \\
(11.1 \%)\end{array}$ & 0.09 \\
\hline
\end{tabular}


There were non-significant statistical relationships between hand disorders among diabetic cases and manual labor, type of therapy and gender except for LMJ and manual labor $(P>0.05)$ as shown in Table 4. The most important predictors of hand disorders among diabetic patients are shown in Tables 5-7 as described below: - HbA1c: Patients with HbA1c levels of less than 6.5 units associated with protective effects against developing hand disorders. Odds ratios were much less than one in LMJ, DC and TF. Patients with controlled diabetes had less chance to develop hand disorders.
- MVC: Presence of MVC associated with increased risks of developing LMJ by 2.2 times, TF by 8.7 times while it was protective for DC but these findings were statistically not significant $(P>0.05)$.

- Manual labor: Diabetic patients who were manual laborer had greater chance to develop LMJ by 7.7 times compared to non -manual laborers, while it had no effects on developing DC and TF.

- Gender: Being male was associated with increased risk of developing TF by approximately four times in contrast it had a decreased risk of acquiring LMJ and DC.

Table 4: Distribution of hand disorders among cases in relation to manual labor, type of therapy and gender.

\begin{tabular}{|c|c|c|c|c|c|c|c|c|c|c|}
\hline \multirow[t]{2}{*}{ Variable } & \multicolumn{2}{|c|}{ Manual labour } & \multirow[b]{2}{*}{$\mathbf{P}$} & \multicolumn{3}{|c|}{ Type of therapy } & \multicolumn{4}{|c|}{ Gender } \\
\hline & $\begin{array}{c}\text { Yes } \\
(n=35)\end{array}$ & $\begin{array}{c}\text { No } \\
(n=37)\end{array}$ & & $\begin{array}{c}\text { Insulin } \\
(n=11)\end{array}$ & $\begin{array}{c}\text { Oral } \\
(n=56)\end{array}$ & $\begin{array}{l}\text { Both } \\
(n=5)\end{array}$ & $\mathbf{P}$ & $\begin{array}{c}\text { Male } \\
(n=32)\end{array}$ & $\begin{array}{c}\text { Female } \\
(n=40)\end{array}$ & $\mathbf{P}$ \\
\hline LJM & $\begin{array}{c}29 \\
(61.7 \%)\end{array}$ & $\begin{array}{c}18 \\
(38 . \%)\end{array}$ & 0.01 & $\begin{array}{c}7 \\
(14.9 \%)\end{array}$ & $\begin{array}{c}37 \\
(78.7 \%)\end{array}$ & $\begin{array}{c}3 \\
(6.4 \%)\end{array}$ & 0.95 & $\begin{array}{c}20 \\
(42.5 \%)\end{array}$ & $\begin{array}{c}27 \\
(57.5 \%)\end{array}$ & 0.11 \\
\hline DC & $\begin{array}{c}3 \\
(18.7 \%)\end{array}$ & $\begin{array}{c}13 \\
(81.3 \%)\end{array}$ & 0.08 & $\begin{array}{c}2 \\
(12.5 \%)\end{array}$ & $\begin{array}{c}13 \\
(81.3 \%)\end{array}$ & $\begin{array}{c}1 \\
(6.2 \%)\end{array}$ & 0.98 & $\begin{array}{c}6 \\
(37.5 \%)\end{array}$ & $\begin{array}{c}10 \\
(62.5 \%)\end{array}$ & 0.23 \\
\hline TF & $3(\%)$ & $6(\%)$ & 0.76 & $\begin{array}{c}2 \\
(22.2 \%)\end{array}$ & $\begin{array}{c}6 \\
(66.7 \%)\end{array}$ & $\begin{array}{c}1 \\
(11.1 \%)\end{array}$ & 0.56 & $\begin{array}{c}6 \\
(66.7 \%)\end{array}$ & $\begin{array}{c}3 \\
(33.3 \%)\end{array}$ & 0.32 \\
\hline
\end{tabular}

Table 5: Predictors LMJ among diabetic patients.

\begin{tabular}{lcccc}
\hline LMJ & Sig. & O.R & 95\% O.R & B \\
\hline HbA1c & 0.001 & 0.115 & $0.03-0.3$ & -2.167 \\
Duration & 0.679 & 0.798 & $0.2-2.3$ & -0.226 \\
MVC & 0.150 & 2.224 & $0.7-6.6$ & 0.799 \\
Manual & 0.001 & 7.774 & $2.5-23.7$ & 2.051 \\
Treatment (insulin) & 0.950 & 1.418 & $0.13-14.7$ & 0.350 \\
Gender (male) & 0.192 & 0.508 & $0.18-1.4$ & -0.677 \\
\hline
\end{tabular}


Table 6: Predictors of DC among diabetic patients.

\begin{tabular}{lcccc}
\hline DC & Sig. & O.R & $95 \%$ O.R & B \\
\hline HbA1c & 0.005 & 0.040 & $0.004-0.37$ & -3.224 \\
Duration & 0.575 & 1.466 & $0.38-5.5$ & 0.382 \\
MVC & 0.116 & 0.344 & $0.09-1.3$ & -1.068 \\
Manual & 0.008 & 0.133 & $0.3-0.58$ & -2.021 \\
Treatment (insulin) & 0.631 & 1.861 & $0.04-12.5$ & -0.343 \\
Gender (male) & & & & -1.108 \\
\hline
\end{tabular}

Table 7: Predictors of TF among diabetic patients.

\begin{tabular}{lcccc}
\hline TF & Sig. & Sig. & 95\% 0.R & B \\
\hline HbA1c & 0.998 & 0.050 & $0.001-0.06$ & -19.212 \\
Duration & 0.933 & 1.071 & $0.21-5.27$ & 0.069 \\
MVC & 0.072 & 8.736 & $0.82-92.78$ & 2.167 \\
Manual & 0.756 & 0.766 & $0.14-4.09$ & -0.266 \\
Treatment (insulin) & 0.571 & 0.464 & $0.32-6.6$ & 0.711 \\
Gender (male) & 0.130 & 3.894 & $0.67-22.6$ & 1.359 \\
\hline
\end{tabular}




\section{Discussion}

Our study showed three important findings. First, the hand soft tissue changes were more prevalent and more severe compared with non-diabetic controls and its present in $(60 \%)$ of our cases. Second, the most common hand change was LJM (47\% of cases). Third, there was a significant association between poor glycemic control and the development of hand changes. Similarly, the prevalence of hand disorder is reported in the Mota. et al study where the prevalence was $50 \% .^{15}$ LJM was common in diabetic patients with prevalence of $(47 \%)$ compared to controls with a prevalence of (18\%), this is in line with Pandey et al. study, ${ }^{16}$ in addition, the diabetic patient had severe forms of LJM according to Brink-Starkman classification system (stage 2 and more); about (16\%) had stage 2, (24\%) had stage 3 and $(6 \%)$ had stage 4 (Table 8). Of the two tests to identify LJM, the prayer sign was relatively more sensitive than the table test. In the prayer sign test, where the palms of the hands are placed against each other, the early lesions in either hand are magnified compared with when each hand is placed separately on a table for the table test. In our study, LJM is associated with poor glycemic control and macrovascular complications which is associated with increased risks of developing LMJ by 2.2 times, and with manual labour since diabetic patients who were manual labourer had greater chance to develop LMJ by 7.7 times compared to non-manual laborers, this finding is in line with those reported by other authors, ${ }^{17}$ regarding the gender being female was associated with increased risk of developing LJM. Dupuytren's contracture has been reported in $(16 \%)$ of diabetic patients compared to controls with a prevalence of (2\%). Physical therapy may be beneficial for early or mild cases. Varied success has been reported with local corticosteroid injections. Surgical intervention may be needed for severe cases. $^{18}$ DC is associated with a poor glycemic control which is statistically significant, also with the female gender. In the present study, the prevalence of trigger finger did not differ between patients and controls, (9\%) of cases and (6\%) of control and the overall prevalence was low in both groups. Of those who had trigger finger, there was a significant correlation between poor glycemic control and macrovascular the complications which associated with increased risks of TF by 8.7 times. Also, TF was associated with gender since the male gender was associated with increased risk of developing TF by

Table 8: LJM stages among cases and controls $(P=0.001)$.

\begin{tabular}{lccc}
\hline LJM stages & \multicolumn{2}{c}{ Study group } & Total \\
\hline 0 & 53 & Controls & 135 \\
& $(53 \%)$ & 82 & $(67.5 \%)$ \\
1 & 1 & $(82 \%)$ & 8 \\
& $(1 \%)$ & 7 & $(4 \%)$ \\
2 & 16 & $(7 \%)$ & 27 \\
& $(16 \%)$ & 11 & $(13.5 \%)$ \\
3 & 24 & $(11 \%)$ & 24 \\
& $(24 \%)$ & 0 & $(12 \%)$ \\
4 & 6 & $(0 \%)$ & 6 \\
& $(6 \%)$ & 0 & $(3 \%)$ \\
Total & 100 & $(0 \%)$ & 200 \\
& $(100 \%)$ & 100 & $(100 \%)$ \\
\hline
\end{tabular}


approximately four times. Our study showed associations between hand soft tissue changes in T2DM patients with poor glycemic control which was the most important predictor and affect the three types of hand deformities in our study, this is in line with the findings obtained in a British cohort that demonstrated a strong association between musculoskeletal manifestations and poor blood glucose control. ${ }^{19}$ Vascular complications are another important predisposing factor, since the presence of MVC associated with increased risks of developing LMJ by 2.2 times, TF by 8.7 times while it was protective for DC but these findings were statistically not significant. This is in line with Ardic et al. study. ${ }^{20}$ The strengths of the present study include a good number of patients with type 2DM along with their matched controls who were assessed for hand soft tissue changes as well as other diabetic complications. The limitations include a lack of objective assessment of functional impairment by measuring hand strength to grade the disability caused by these hand changes. Also, the lack of baseline data for our population to allow comparative projections of these changes with increasing duration of diabetes is an inevitable weakness of cross-sectional studies.

\section{Conclusion}

The examination of periarticular regions of the hands and its joints should be included in the evaluation of patients with DM because the hand disorders are common in patients of type 2 DM and many of these complications are potentially treatable, especially if diagnosed early. LJM is the most common hand disorder present in type 2 DM. Most of the hand disorders seem to be associated with poor glycemic control and macrovascular complications.

\section{Conflicts of interest}

The authors report no conflicts of interest.

\section{References}

1. Egede LE. Diabetes, major depression, and functional disability among U.S. adults. Diabetes Care. 2004; 27: 421-8.

2. Ikem RT, Kolawole BA, Olasode O. A descriptive study of foot complications in diabetic patients with symptomatic peripheral neuropathy. Afr J Neurol Sci 2005; 24:7-12.

3. Lekholm C, Sundkvist G, Lundborg G, Dahlin L. The diabetic hand complication of diabetes. Ann Rheum Dis. 2001; 98:306-12.

4. Fam AG. Regional pain problems. In: Klippel JH, Dieppe PA, eds. Practical Rheumatology. London, England: Mosby; 1997.

5. Blyth MJ, Ross DJ. Diabetes and trigger finger. J Hand Surg 1996; 21B:244-5.

6. Trojian TH, Chu SM. Dupuytren's disease: diagnosis and treatment. Am Fam Physician 2007;76(1):86-9.

7. Black EM, Blazar PE. Dupuytren disease: an evolving understanding of an age-old disease. J Am Acad Orthop Surg 2011;19(12):746-57.

8. Kiani J, Goharifar H, Moghimbeigi A, Azizkhani H. Prevalence and Risk Factors of Five Most Common Upper Extremity Disorders in Diabetics. J Res Health Sci 2014;14(1):93-6.

9. American Diabetes Association. Standards of medical care for patients with diabetes mellitus. Diabetes Care 2003; 26(Suppl 1): S33-50.

10. Lekholm C, Sundkvist G, Lundborg G, Dahlin L. The diabetic hand-complication of diabetes. Ann Rheum Dis 2001;98:306-12.

11. Starkman $H$, Brink S. Limited joint mobility(LJM) of the hand in patient with diabetes mellitus. Diabetes Care 1982;5:534-6.

12. Suzan M. Musculoskeletal manifestations in diabetic patients at a tertiary center. Libyan J Med 2012; 7(1):19162.

13. Beckman JA, Creager MA, Libby $P$. Diabetes and atherosclerosis: epidemiology, pathophysiology, and management. JAMA 2002; $287: 2570-81$

14. International Expert Committee report on the role of the A1C assay in the diagnosis of diabetes. Diabetes Care 2009;32:1327-34.

15. Mota M, Panus C, Mota E, Sfredel V, Patrascu A, Vanghelie L, et al. Hand abnormalities of the patients with diabetes mellitus. Rom J Intern Med 2001; 38-39:89-95.

16. Pandey A, Usman $K$, Reddy $H$, Gutch $M$, Jain N, Qidwai SA. Prevalence of Hand Disorders in Type 2 Diabetes Mellitus and its Correlation with Microvascular Complications. Ann Med Health Sci Res 2013; 3(3):349-54.

17. Loos B, Puschkin V, Horch RE. 50 years experience with Dupuytren's contracture in the Erlangen University hospital: A retrospective analysis of 2919 operated hands from 1956 to 2006. BMC Musculoskelet Disord 2007;8: 60. 
18. Ramchurn N, Mashamba C, Leitch E, Arutchelvam V, Narayanan K, Weaver J, et al. Upper limb musculoskeletal abnormalities and poor metabolic control in diabetes. Eur J Intern Med 2009; 20: 718.

19. Savas S, Koroglu BK, Koyuncuoglu HR, Uzar E, Celik H, Tamer NM. The effects of the diabetes related soft tissue hand lesions and the reduced hand strength on functional disability of hand in type 2 diabetic patients. Diabetes Res Clin Pract 2007; 77:77-83.

20. Ardic F, Soyupek F, Kahraman Y, Yorgancioglu $\mathrm{R}$. The musculoskeletal involvement seen in type 2 diabetes. Clin Rheumatol 2003; 22:229-33. 